Çukurova Üniversitesi Mühendislik Mimarlık Fakültesi Dergisi, 30(1), 151-166 ss., Haziran 2015

Çukurova University Journal of the Faculty of Engineering and Architecture, 30(1), pp. 151-166, June 2015

\title{
Dikim Bandında Bir Proses Analizinin Uygulaması
}

\author{
Melike CÖMERT ${ }^{1}$, Füsun DOBA KADEM ${ }^{* 2}$ \\ ${ }^{1}$ Tekstil Mühendisi \\ ${ }^{2}$ Çukurova Üniversitesi Mühendislik-Mimarlık Fakültesi, Tekstil Mühendisliği Bölümü, Adana \\ Geliş tarihi: 02.04 .2015 \\ Kabul tarihi: 24.06 .2015
}

\section{Özet}

$\mathrm{Bu}$ çalışmada seçilmiş bir konfeksiyon işletmesinde farklı desenli iki çift pantolonun dikim prosesi incelenmiştir. Giysilerin dikim hattı için zaman ölçümü ve proses analizi yapılmıştır. Pitch time hesaplanmış, Pitch şeması oluşturulmuş, proses analizinde dar boğazlar tespit edilmiş ve ilgili çözüm önerileri sunulmuştur.

Anahtar kelimeler: Proses analizi, Standart süre, Darboğaz, Dikiş prosesi

\section{Implementation of a Process Analysis in Sewing Line}

\begin{abstract}
In this study, sewing process of two pair of trousers with different pattern was researched in a selected garment factory. Time measurement and process analysis of the garments were carried out for their sewing line. Pitch time was calculated, pitch schema was formed and bottlenecks at the process analysis were determined and related solutions were offered.
\end{abstract}

Keywords: Process analysis, Standard time, Bottleneck, Sewing process

\footnotetext{
* Yazışmaların yapılacağı yazar: Füsun DOBA KADEM, Çukurova Üniversitesi, Müh. Mim. Fakültesi, Tekstil Müh. Bölümü, Adana. fusundobakadem@gmail.com
} 


\section{GİRIŞ}

Konfeksiyon sektörü sürekli değişebilen yapısıyla dinamik bir sektördür. Hammadde, yardımcı madde ve model yapısının kısa sürede değişimi ile üretimin devamlılı̆̆ 1 kolaylıkla sağlanabilmektedir. Bu yüzden de hem ülkemizde hem de dünyada önemli bir sektör olmaya devam etmektedir. Türkiye İhracatçılar Meclisi tarafından açıklanan verilere göre, 2014 yılında Türkiye'den 18,7 milyar dolar değerinde hazırgiyim ve konfeksiyon ihracatı yapılmıştır. 2013 yılına kıyasla ihracatta, dolar bazında \%8 oranında artış meydana gelmiştir. Hazırgiyim ve konfeksiyon sektörü, 2014 yılında ihracatı $\% 4,5$ oranında artan otomotiv endüstrisinin ardından, en fazla ihracat yapan ikinci sektör konumundadır. 2014 y1lında örme konfeksiyon mamullerinin toplam hazırgiyim ve konfeksiyon ihracatındaki payı \%54,3, dokuma konfeksiyon mamullerinin payı \%33,7 ve hazır eşyaların payı \%12 olmuştur [1]. Konfeksiyon sektörünün emek yoğun olması dolayısıyla bu sektörde insan faktörünün üretim verimliliğini doğrudan etkilemesi, bu kapsamda yapılan iş etüdü çalışmalarını ön plana çıkarmaktadır. İş etüdü, gelişme olanağı yaratabilmek amacıyla, belirli bir olayı ya da etkinliği ekonomiklik ve etkenlik yönünden etkileyen tüm kaynakları ve etmenleri dizgesel olarak araştırmaya yönelik ve insan çalışmasını geniş kapsamda inceleyen bir teknik olup özellikle iş ölçümü ve zaman etüdü teknikleri için kullanılan genel bir terimdir. İş etüdü verimlikle doğrudan ilişkilidir. $\mathrm{Bu}$ nedenle mevcut kaynaklardan sağlanacak üretimi, çok az ya da hiç yatırım gerektirmeksizin, artırmak amacıyla çok yaygın olarak kullanılmaktadır [2]. Verimlilik kavramının öneminin giderek artması günümüz konfeksiyon sektöründe verimlilik ölçümüne gereken önemin verilmesini sağlamıştır. İşletmeler yönünden verimliliğin doğru olarak ölçülebilmesi kaynakların etkin olarak kullanılıp kullanılmadığını göstermesi yönünden önemlidir. Kanat ve Güner'in çalışmasında tekstil ve hazır giyim işletmelerinde uygulanmakta olan verimlilik ölçüm yöntemleri tartışılmıştır. Verimlilik kavramının doğru olarak ölçülmesi firmanın kaynaklarını etkin olarak kullanıp kullanmadığını göstermesi açısından oldukça önemli olduğu vurgulanmıştır. Bu sonuçların doğru olarak analiz edilmesi ve gerekli tedbirlerin alınması firmanın verimliliğini artırmasını sağlayacağı sonucuna ulaşılmıştır [3]. Duru Baykal ve Tunç; bornoz üretimi yapan bir işletmede seçilen bir bornoz için konfeksiyon sürecini incelemiştir. İnceledikleri bornoz için dikim bölümünde dikim adımlarını inceleyerek, zaman ölçümü ve proses analizi yapmıştır. Pitch Time hesaplamış, Pitch şeması oluşturmuş, proses analizinde dar boğazları tespit etmiştir. Dar boğazların giderilmesine ve dikim bandı verimliliğinin artırılmasına yönelik çözüm önerileri sunmuştur [4]. Yücel ve Güner; konfeksiyon üretiminde giysi dikim süresine etki eden faktörleri analiz etmiştir. Araştırmada birim zamana etki eden faktörler hesaplamıştır. İstatistiksel analiz sonucunda bu faktörlere bağlı olarak birim dikim zamanı denklemi oluşturmuştur. $\mathrm{Bu}$ denklem yardımıyla dikim zamanlarına etki eden faktörlerin daha etkin yönetimi ve kontrolü sağlanabileceğini saptamıştır. İncelenen faktörlerden kumaş ağırlığı ve dikiş adım sayılarının birim zamana etkilerinin önemsiz olduğu, diğer faktörlerin ise belirlenen istatistiksel güven sınırları içerisinde önemli olduğu sonucuna ulaşmıştır [5]. Duru Baykal ve Göçer; bir konfeksiyon işletmesinde farklı kumaş türleri ile farklı modellerin çalışılması sırasında verimlilik ve kalite değerlendirmiştir. Çalışma kapsamında seçtikleri modellerin proses sayıları ve süreleri, kesim yerleşim planı (pastal resmi) verimlilikleri, bant verimlilikleri ile ikinci kalite oranlarını tespit etmiş, karşılaştırmıştır. Kumaşların ve modellerin işletmede çalışmaya uygunluğunu belirlemeye çalışmıştır [6]. Kansoy ve Erdoğan, giysi türlerine ait farklı model özelliklerinin dikim süresi üzerinde nasıl bir etkiye sahip olduklarının incelenmesini amaçlamıştır. Ürün gruplarında farklı giysi modelleri oluşturarak, parça sayısı ve parça çevresi özelliklerinin dikim süresine etkilerinin nasıl olacağını araştırmıştır. Model özellikleri değişiminin dikim süresine etkisini ortaya koymuştur. Tüm modellerde parça sayısı ve parça çevresinin artmasının dikim süresini artırdığı sonucuna ulaşılmıştır [7].

\section{MATERYAL VE METOT}

Çalışma kapsamında \%100 polyester dokuma 
kumaş bayan pantolonu incelenmiş, incelenen ürünlerin kumaş özellikleri aynı olmakla beraber biri çizgili baskılı (1 nolu) diğeri düz fuşya renginde (2 nolu) pantolondur. Pantolonların dikilmiş son halleri Şekil 1'de gösterilmiştir.

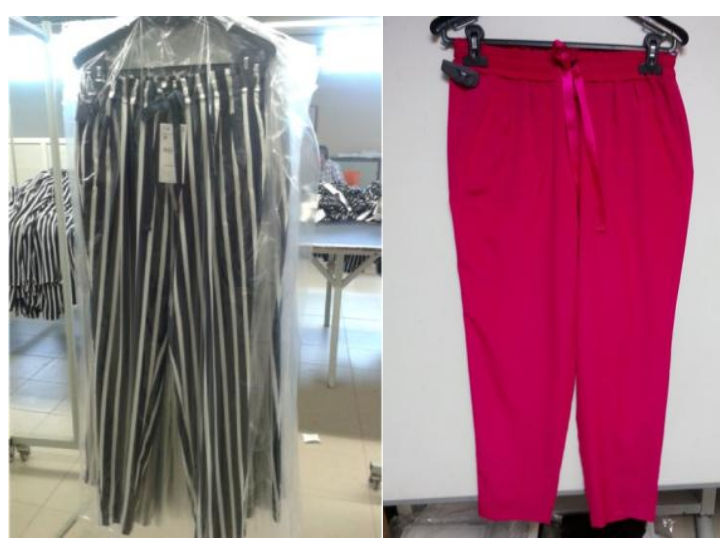

(1)

(2)

Şekil 1. Pantolon dikim sonrası görünümleri [8]

\subsection{Model Bilgileri}

Pantolon modeli beli lastikli ve biyeli arkası ve önü cepli paçaya doğru hafif daralan bir modeldir. İşletmede çalışan operatörlerin dikimine alışkın olduğu bir modeldir. Pantolon modeli teknik çizimi ise Şekil 2'de gösterilmiştir [8].

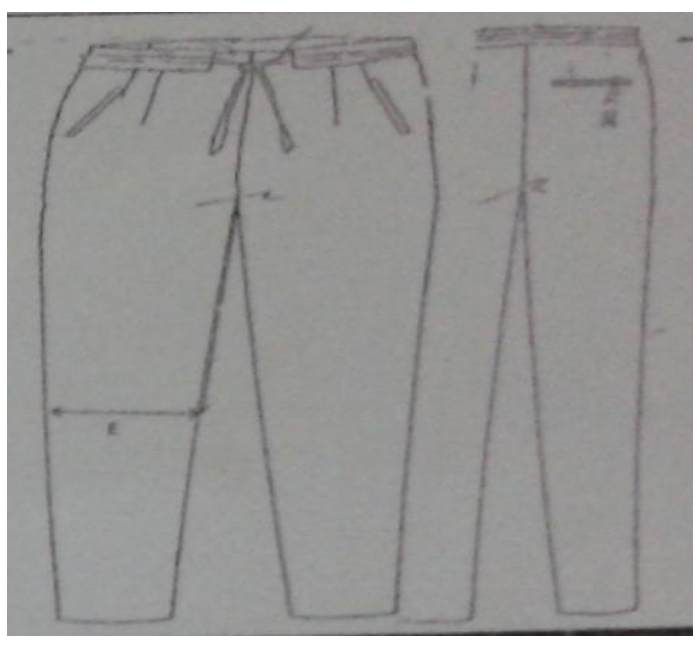

Şekil 2. Pantolon teknik çizimi [8]

\subsection{Metot}

Proses analizi uygulama çalışmasında bant boyunca her işlem adımının proses süreleri hesaplanmıştır. Proses sürelerinin belirlenmesinde zaman etüdü sürekli ölçme tekniğine göre yapılmıştır. Sürekli ölçme tekniğinde işlemin başında kronometre çalıştırılır. Bir sonraki çalışma unsuruna gelince kronometredeki rakam kaydedilir fakat kronometre durdurulmaz. Gözlem bittikten sonra kaydedilen her değer kendinden bir önceki değerden çıkartılarak o işlemin süresi bulunur. $\mathrm{Bu}$ çalışmada her bir proses için ayrı ayrı 20'şer ölçüm yapılarak ortalama alınmıştır. Ardından ortalama değerlere \%20'lik tolerans payı eklenerek her işleme ait standart zamanlar belirlenmiştir. Tolerans payı işçilerin becerisine, model tipine, çalışma detaylarına bağlı olarak \%20-25 arasında değişmektedir $[9,10]$. Çizelge 1 ve 2 'de her iki modele ait paça katlama proses süreleri gösterilmektedir.

Çizelge 1. 1 nolu ürün paça katlama proses süresi

\begin{tabular}{|c|c|}
\hline $\begin{array}{c}\text { Ölçüm } \\
\text { Sayısı }\end{array}$ & $\begin{array}{l}\text { Ölçüm } \\
\text { Süresi }\end{array}$ \\
\hline 1 & 21 \\
\hline 2 & 19 \\
\hline 3 & 20 \\
\hline 4 & 23 \\
\hline 5 & 19 \\
\hline 6 & 21 \\
\hline 7 & 23 \\
\hline 8 & 18 \\
\hline 9 & 23 \\
\hline 10 & 19 \\
\hline 11 & 18 \\
\hline 12 & 17 \\
\hline 13 & 23 \\
\hline 14 & 19 \\
\hline 15 & 22 \\
\hline 16 & 19 \\
\hline 17 & 19 \\
\hline 18 & 19 \\
\hline 19 & 21 \\
\hline 20 & 18 \\
\hline Ortalama & 20,05 \\
\hline
\end{tabular}


Çizelge 2. 2 nolu ürün paça katlama proses süresi

\begin{tabular}{|c|c|}
\hline $\begin{array}{l}\text { Ölçüm } \\
\text { Sayısı }\end{array}$ & Ölçüm Süresi \\
\hline 1 & 26 \\
\hline 2 & 25 \\
\hline 3 & 22 \\
\hline 4 & 23 \\
\hline 5 & 22 \\
\hline 6 & 23 \\
\hline 7 & 22 \\
\hline 8 & 19 \\
\hline 9 & 26 \\
\hline 10 & 23 \\
\hline 11 & 21 \\
\hline 12 & 21 \\
\hline 13 & 28 \\
\hline 14 & 28 \\
\hline 15 & 28 \\
\hline 16 & 23 \\
\hline 17 & 17 \\
\hline 18 & 17 \\
\hline 19 & 24 \\
\hline 20 & 28 \\
\hline Ortalama & 23,3 \\
\hline
\end{tabular}

İncelenen pantolon modelinde 1 nolu ürünün 33 adet, 2 nolu ürünün 32 adet dikim adımı bulunmaktadır. Her iki pantolona ait hesaplanan standart süreler Çizelge 3 ve 4 'te gösterilmektedir.

\subsubsection{Proses Analizi}

Dikimhanede ekip çalışmasının önemini ortaya koyan analiz metodu proses analizi olarak tanımlanır. Amacı operasyonların (dikiş adımlarının) proses sırasını açıklığa kavuşturmak ve karmaşık prosesleri sembollerle daha kolay anlaşılır şekilde ifade etmektir. Proses analizi; prosesleri geliştirir, üretim planı ve proses kontrolü için gerekli bilgileri verir $[9,10]$. Proses analizinde aşağıdaki sembollerden faydalanılır.

Proses analizi tablosu oluşturulurken belirli adımlar takip edilir. Birleştirilecek olan parçalar; yapılacak işlem adımına göre çeşitli şekiller ile gösterilerek proses şeması oluşturulur. Birleştirme prosesi uygulanırken sağ kısıma proses adı ve kullanılacak makineler; sol kısıma ise net üretim süresi yazılır. Birleştirme prosesi örneği Şekil 3 'te gösterilmiştir. 1 ve 2 nolu ürünlerin proses analiz tablosu hazırlanarak Şekil 4 ve Şekil 5'te gösterilmiştir.

\subsubsection{Nolu Ürünün Dikim Bandı Verimlilik Artırma Çalışmaları}

Dikim bandında çalışmanın senkronizasyonu için yapılması gerekenler aşağıda verilmiştir.

Pitch Time (PT): Bant içinde aynı anda çalışmayı sürdürmek için kullanılan temel süredir. Bu süre hesaplanırken banttaki bütün işçilerin aynı anda ekip olarak çalışmayı sürdürmesi koşulu esas alınır ve aşağıdaki şekilde hesaplanır;

$$
\begin{aligned}
& \text { PT }=\text { Üretim Süresi / İşçi Sayısı } \\
& \text { UPT }=\text { PT / OV } \\
& \text { LPT }=2 \times \text { PT }- \text { ÜPT }
\end{aligned}
$$

\section{PT : Pitch Time}

LPT : Alt Kontrol Sinırı

UPT : Üst Kontrol Sinır1

OV : Organizasyon Verimliliği

(Bant Organizasyonunun verimliliği en az \%85 olacak şekilde organize edilmelidir) $[4,9,11]$.

1 nolu ürün için hesaplanan standart üretim süresi 602,28 saniye, işçi sayısı ise 56'dır. Buna göre yapilan hesaplamalarda;

$\mathrm{PT}=602,28 / 56=10,75 \mathrm{sn}$

$\mathrm{UPT}=10,75 / 0,85=12,64 \mathrm{sn}$

$\mathrm{LPT}=2 \times 10,75-12,64=8,86 \mathrm{sn}$

olarak hesaplanır. Hesaplanan Pitch Time değeri ile her bir işlem grubunda çalışması gereken işçi sayıs1 hesaplaması yapılabilir. 1 nolu üründe her bir işlem için çalışması gereken işçi sayıları; düz dikiş için 23, overlok ve fileto dikiş için 13, çift iğneli ve tek iğneli dikiş için 8 , el işi ve ütü için 11 ' dir. Her bir prosesin işçi sayısına bölünerek hesaplanan proseslere ayrılan süreler Çizelge 6 'da 
Çizelge 3. 1 nolu ürün standart proses süresi

\begin{tabular}{|c|c|c|c|c|c|}
\hline $\begin{array}{c}\text { Proses } \\
\text { No }\end{array}$ & Proses Adı & $\begin{array}{c}\text { Ortalama } \\
\text { Proses Süresi }\end{array}$ & $\begin{array}{c}\text { Standart } \\
\text { Proses Süresi }\end{array}$ & $\begin{array}{c}\text { Operatör } \\
\text { Sayısı }\end{array}$ & Proses Çeşidi \\
\hline 1 & Fileto Yeri İșaretleme & 5,9 & 7,08 & 1 & El İși \\
\hline 2 & Ön Fileto Dikimi & 13,75 & 16,5 & 1 & Fileto Makinesi \\
\hline 3 & Ön Cep Açma & 14,9 & 17,88 & 2 & El İși \\
\hline 4 & Cep Uçları Dikimi & 14,9 & 17,88 & 1 & Düz Dikiș Makinesi \\
\hline 5 & Ön Astar Montaj Dikimi & 22,35 & 26,82 & 2 & Düz Dikiş Makinesi \\
\hline 6 & Ön Cep Pile Dikimi & 9,75 & 11,7 & 3 & Düz Dikiş Makinesi \\
\hline 7 & Ön Cep Karșılı̆̆ İçi Dikimi & 9,75 & 11,7 & 1 & Düz Dikiș Makinesi \\
\hline 8 & Ön Cep Yan Dikimi & 8,05 & 9,66 & 2 & Overlok Makinesi \\
\hline 9 & Arka Fileto Dikimi & 11,7 & 14,04 & 2 & Fileto Makinesi \\
\hline 10 & Arka Cep Açma & 13,45 & 16,14 & 1 & El İși \\
\hline 11 & Arka Cep Dikimi & 15,45 & 18,54 & 1 & Düz Dikiș Makinesi \\
\hline 12 & $\begin{array}{l}\text { Arka Cep Karşılığı Montaj } \\
\text { Dikimi }\end{array}$ & 13,9 & 16,68 & 1 & Düz Dikiş Makinesi \\
\hline 13 & $\begin{array}{l}\text { Arka Cep Karşıllığı Overlok } \\
\text { Dikimi }\end{array}$ & 11,3 & 13,56 & 3 & Overlok Makinesi \\
\hline 14 & Arka Ön Cep Eşleme Dikimi & 7,8 & 9,36 & 1 & Düz Dikiș Makinesi \\
\hline 15 & Yan Bacak Overlok Dikimi & 12,75 & 15,3 & 2 & Overlok Makinesi \\
\hline 16 & Bacak Arası Overlok Dikimi & 18,8 & 22,56 & 3 & Overlok Makinesi \\
\hline 17 & Arka Çatım Dikimi & 22,75 & 27,3 & 2 & Overlok Makinesi \\
\hline 18 & Kemer Çevirme & 20,9 & 25,08 & 2 & El İși \\
\hline 19 & Kemer Kapama Dikimi & 17,8 & 21,36 & 1 & Çift İğneli Dikiș Makinesi \\
\hline 20 & Kemer Dikimi & 20,05 & 24,06 & 2 & Düz Dikiș Makinesi \\
\hline 21 & $\begin{array}{l}\text { Lastik Biye Birleștirme } \\
\text { Dikimi }\end{array}$ & 10,25 & 2112,3 & 1 & Düz Dikiș Makinesi \\
\hline 22 & Kemer Ucu Dikimi & 14 & 1186,8 & 2 & Düz Dikiș Makinesi \\
\hline 23 & Kemer Ütüleme & 10,65 & 12,78 & 1 & Ütü \\
\hline 24 & Biye Ucu Kıvırma Dikişi & 15,15 & 18,18 & 2 & Düz Dikiş Makinesi \\
\hline 25 & Kemer Ucu Birleștirme Dikiși & 11,3 & 13,56 & 1 & Düz Dikiș Makinesi \\
\hline 26 & Kemer Çatım Dikimi & 20,65 & 24,78 & 2 & Düz Dikiș Makinesi \\
\hline 27 & Marka Etiketi Dikimi & 16,8 & 20,16 & 2 & Düz Dikiş Makinesi \\
\hline 28 & Y1kama Etiketi Dikimi & 10,75 & 12,9 & 1 & Düz Dikiş Makinesi \\
\hline 29 & Pervaz Biye Dikimi & 20,3 & 24,36 & 2 & Çift İğneli Dikiş Makinesi \\
\hline 30 & Kuşak Ucu Dikimi & 12,45 & 14,94 & 2 & Tek İğneli Dikiş Makinesi \\
\hline 31 & Kuşak Ucu Geçirme & 33,15 & 39,78 & 2 & El İși \\
\hline 32 & Paça Katlama & 20,05 & 24,06 & 3 & Tek İğneli Dikiș Makinesi \\
\hline 33 & Paça Overlok Dikimi & 20,4 & 24,48 & 1 & Overlok Makinesi \\
\hline \multicolumn{2}{|c|}{ TOPLAM } & 501,9 & 602,28 & 56 & \\
\hline
\end{tabular}


Çizelge 4. 2 nolu ürün standart proses süresi

\begin{tabular}{|c|c|c|c|c|c|}
\hline $\begin{array}{c}\text { Proses } \\
\text { No }\end{array}$ & Proses Adı & $\begin{array}{c}\text { Ortalama } \\
\text { Proses Süresi }\end{array}$ & $\begin{array}{c}\text { Standart } \\
\text { Proses Süresi }\end{array}$ & $\begin{array}{c}\text { Operatör } \\
\text { Sayısı }\end{array}$ & Proses Çeşidi \\
\hline 1 & Ön Fileto Dikimi & 11,15 & 13,38 & 1 & Fileto Makinesi \\
\hline 2 & Ön Cep Açma & 10,35 & 12,42 & 1 & El İşi \\
\hline 3 & Cep Uçları Dikimi & 18,4 & 22,08 & 2 & Düz Dikiş Makinesi \\
\hline 4 & Ön Astar Montaj Dikimi & 20,6 & 24,72 & 2 & Düz Dikiş Makinesi \\
\hline 5 & Ön Cep Pile Dikimi & 14,4 & 17,28 & 2 & Düz Dikiş Makinesi \\
\hline 6 & Ön Cep Karşılığ İçi Dikimi & 7,4 & 8,88 & 1 & Düz Dikiş Makinesi \\
\hline 7 & Ön Cep Yan Dikimi & 7,8 & 9,36 & 1 & Overlok Makinesi \\
\hline 8 & Arka Fileto Dikimi & 14,55 & 17,46 & 1 & Fileto Makinesi \\
\hline 9 & Arka Cep Açma & 11,2 & 13,44 & 1 & El İşi \\
\hline 10 & Arka Cep Dikimi & 11,45 & 13,74 & 1 & Düz Dikiş Makinesi \\
\hline 11 & $\begin{array}{l}\text { Arka Cep Karşılığı Montaj } \\
\text { Dikimi }\end{array}$ & 14,4 & 17,28 & 2 & Düz Dikiş Makinesi \\
\hline 12 & $\begin{array}{l}\text { Arka Cep Karşılığı Overlok } \\
\text { Dikimi }\end{array}$ & 9,25 & 11,1 & 1 & Overlok Makinesi \\
\hline 13 & Arka Ön Cep Eşleme Dikimi & 4,7 & 5,64 & 1 & Düz Dikiş Makinesi \\
\hline 14 & Yan Bacak Overlok Dikimi & 15,25 & 18,3 & 3 & Overlok Makinesi \\
\hline 15 & Bacak Arası Overlok Dikimi & 11,5 & 13,8 & 3 & Overlok Makinesi \\
\hline 16 & Arka Çatım Dikimi & 23,05 & 27,66 & 2 & Overlok Makinesi \\
\hline 17 & Kemer Çevirme & 27,2 & 32,64 & 2 & El İşi \\
\hline 18 & Kemer Kapama Dikimi & 8,9 & 10,68 & 1 & $\begin{array}{l}\text { Çift İğneli Dikiş } \\
\text { Makinesi }\end{array}$ \\
\hline 19 & Kemer Dikimi & 17,4 & 20,88 & 2 & Düz Dikiş Makinesi \\
\hline 20 & Lastik Biye Birleştirme Dikimi & 12,15 & 14,58 & 2 & Düz Dikiş Makinesi \\
\hline 21 & Kemer Ucu Dikimi & 8,35 & 10,02 & 1 & Düz Dikiş Makinesi \\
\hline 22 & Kemer Ütüleme & 13,6 & 16,32 & 1 & Ütü \\
\hline 23 & Biye Ucu Kıvırma Dikişi & 15,6 & 18,72 & 2 & Düz Dikiş Makinesi \\
\hline 24 & Kemer Ucu Birleştirme Dikişi & 16,9 & 20,28 & 1 & Düz Dikiş Makinesi \\
\hline 25 & Kemer Çatım Dikimi & 20,95 & 25,14 & 2 & Düz Dikiş Makinesi \\
\hline 26 & Marka Etiketi Dikimi & 10,3 & 12,36 & 1 & Düz Dikiş Makinesi \\
\hline 27 & Y1kama Etiketi Dikimi & 9,1 & 10,92 & 1 & Düz Dikiş Makinesi \\
\hline 28 & Pervaz Biye Dikimi & 31,85 & 38,22 & 3 & $\begin{array}{l}\text { Çift İğneli Dikiş } \\
\text { Makinesi }\end{array}$ \\
\hline 29 & Kuşak Ucu Dikimi & 12 & 14,4 & 2 & $\begin{array}{l}\text { Tek İğneli Dikiş } \\
\text { Makinesi }\end{array}$ \\
\hline 30 & Kuşak Ucu Geçirme & 36,1 & 43,32 & 4 & El İşi \\
\hline 31 & Paça Katlama & 23,3 & 27,96 & 2 & $\begin{array}{l}\text { Tek İğneli Dikiş } \\
\text { Makinesi }\end{array}$ \\
\hline 32 & Paça Overlok Dikimi & 20,35 & 24,42 & 1 & Overlok Makinesi \\
\hline \multicolumn{2}{|c|}{ TOPLAM } & 489,5 & 587,4 & 53 & \\
\hline
\end{tabular}


Çizelge 5. Dikiş sembolleri [9]

\begin{tabular}{|c|c|}
\hline Sembol & Açıklama \\
\hline & Düz Dikiş Dikme \\
\hline 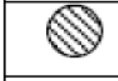 & $\begin{array}{l}\text { Spesiyal Makineler veya aparatlar ile } \\
\text { yapilan dikiş }\end{array}$ \\
\hline (0) & Ütü ve E1 İş̧i \\
\hline (Q) & Pres \\
\hline 0 & Nakil İşi \\
\hline$\square$ & Miktar Kontrolü \\
\hline$\diamond$ & Kalite Kontrol \\
\hline$\nabla$ & $\begin{array}{l}\text { Kesilmiş Hammadde ve Parçaların } \\
\text { Muhafazası }\end{array}$ \\
\hline$\triangle$ & Tamamlanmış Ürünlerin Muhafazası \\
\hline
\end{tabular}

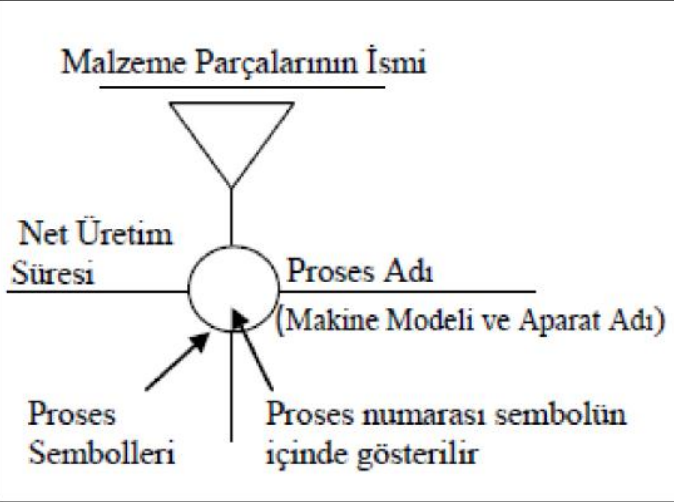

Şekil 3. Birleştirme Prosesi İfade Yöntemi [9]

gösterilmiştir. Benzer prosesler bir arada gruplandırılarak 5 ayrı grup elde edilmiştir. Bu tablodan yararlanılarak Pitch Şeması oluşturulmuştur. Şemada PT, alt limit (LPT) ve üst limit (UPT) değerleri gösterilmektedir.

Şemada bulunan amaçlanan günlük verim miktarı, darboğaz günlük verim miktarı ve organizasyon verim yüzdesi aşağıdaki formüller ile hesaplanmıştır $[4,9,11]$.

Amaçlanan Günlük Verim $=$ Günlük Çalışma Zamanı / PT
Darboğaz Günlük Verim = Günlük Çalışma Zamanı / Darboğaz İşlem Süresi

Organizasyon Verimi $=$ PT $/$ Darboğaz İşlem Süresi

Pitch Şeması, darboğaz noktasının şemadaki en yüksek değer olan 13,19 olduğunu göstermektedir. Dar boğaz noktası verimliliği düşürücü etki yaratmaktadır. $\mathrm{Bu}$ nedenle Pitch Time'a yaklaştırıcı önerilerde bulunularak verimliliğin artırılması hedeflenir. Hesaplanan değerler ve oluşturulan pitch şeması gözlendiğinde el işi ve ütü proseslerinin bulunduğu $1,3,10,18,23$ ve 31 nolu proseslerin standart sürelerinin üst kontrol sınırından bir miktar fazla olduğu görülmektedir.

Proses süresi 13,19 sn, üst kontrol sınırı ise 12,64 sn'dir. 31 nolu kuşak ucu geçirme işlemi, Pitch Time'in altında kalan fileto ve overlok dikişin gruplandırıldığı prosesle birleştirilebilir. $\mathrm{Bu}$ şekilde yapılan hesaplama;

$(118,74-39,78) / 7=11,28$ sn'ye düşürülerek pitch time değerine oldukça yaklaşmış olur .

Böylece yeni dar boğaz süresi 11,28 sn olur.

Fileto ve overlok dikişin bulunduğu proseslerin birleştirilmesiyle oluşan yeni işlem süresi;

$(143,4+39,78) / 18=10,17$ sn'ye yükseltilir. Böylece pitch time sınırına yaklaşmış olur.

PT'ye göre, dikim bandında amaçlanan günlük verim, darboğazın günlük verimi ve organizasyon verimi aşağıdaki formüllerle yeniden hesaplanmaktadır.

\section{Amaçlanan Günlük Verim = Günlük Çalışma Zamani / PT}

Amaçlanan Günlük Verim $=28800 /$ 10,75 $=2679$ adet

Darboğaz Günlük Verim = Günlük Çalışma Zamanı / Darboğaz İşlem Süresi

Darboğaz Günlük Verim $=28800 / 11,28=2553$ adet 


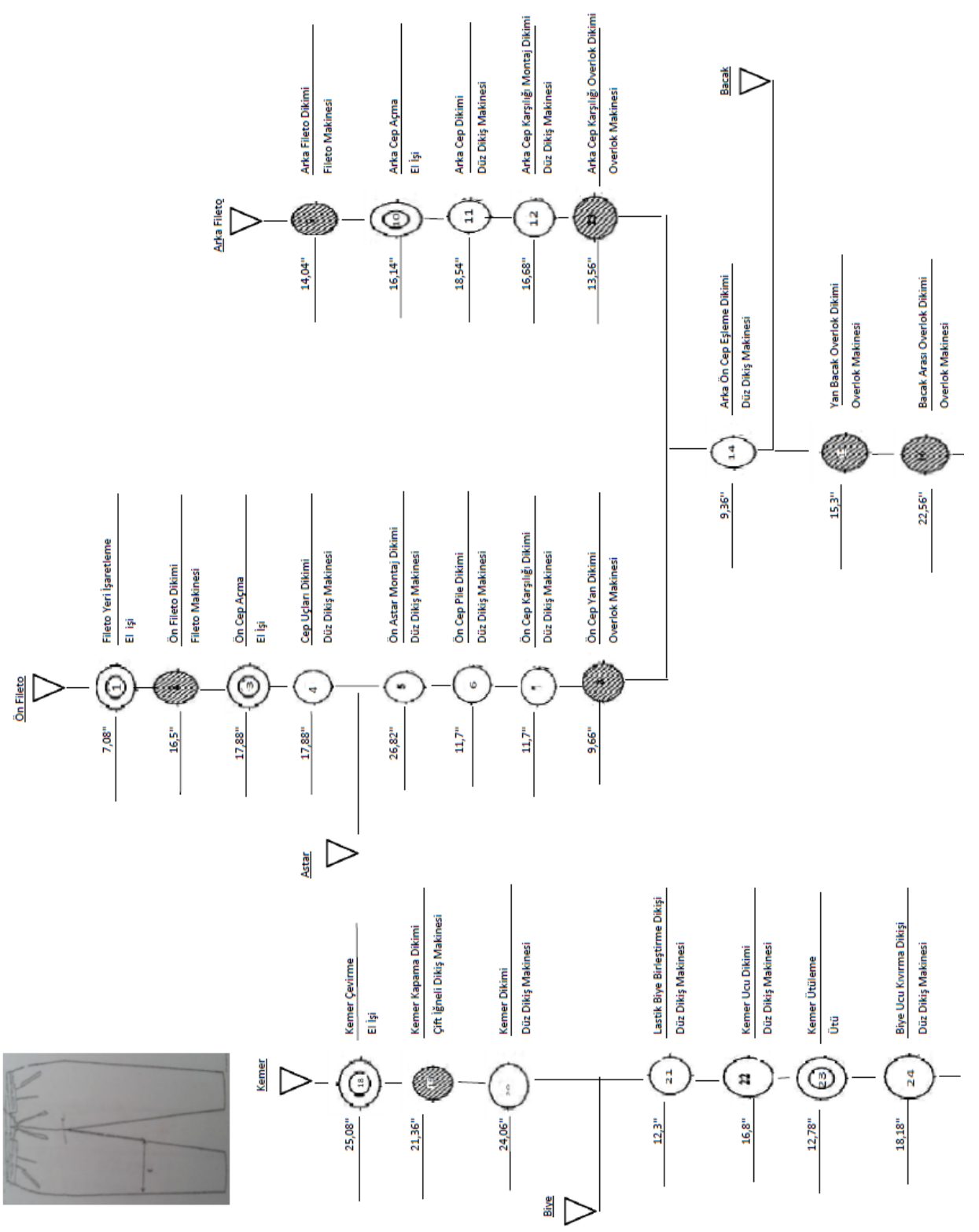

Şekil 4. 1 nolu ürünün proses analiz tablosu 


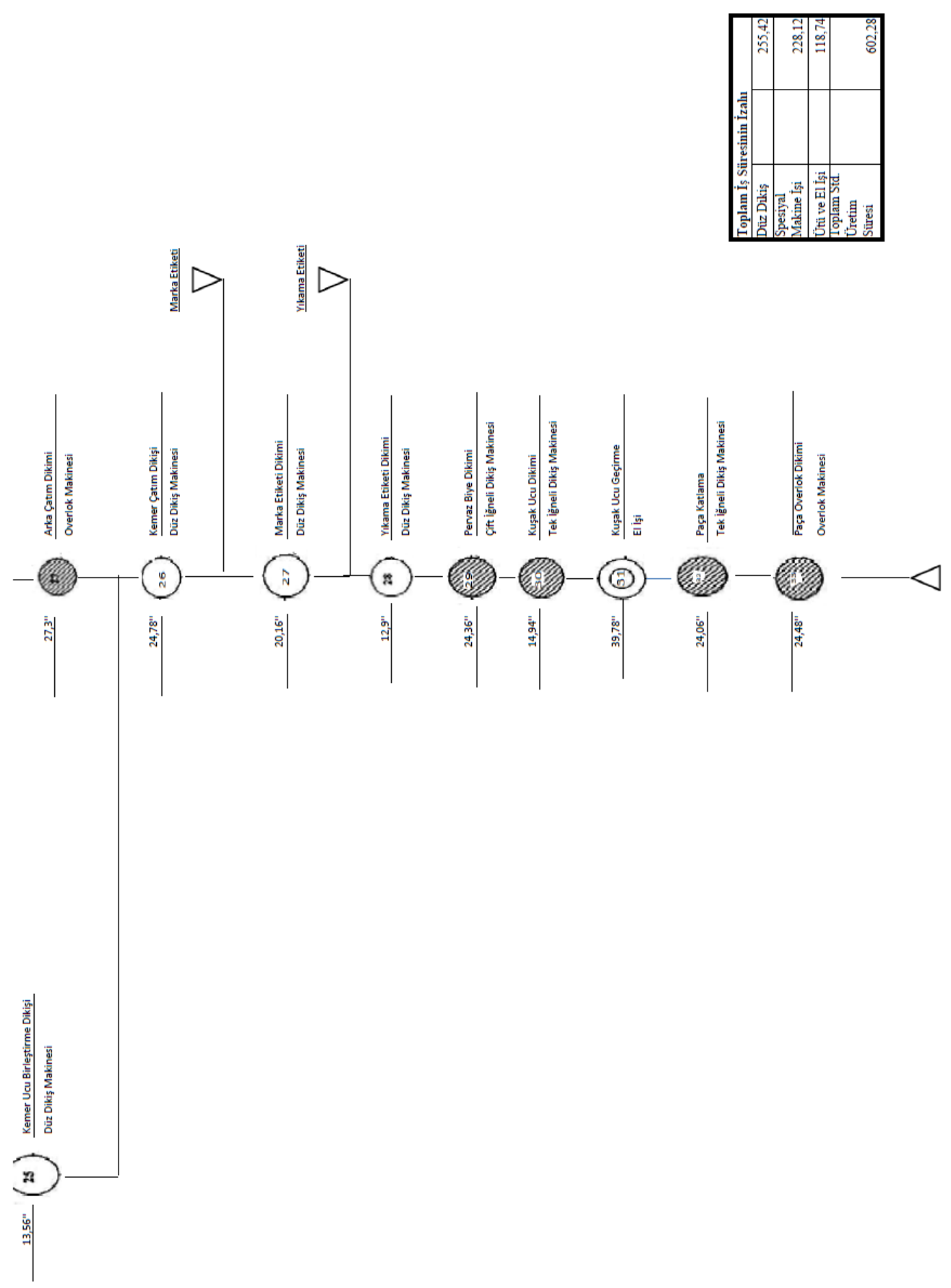

Şekil 4. 1 nolu ürünün proses analiz tablosu (devamı) 


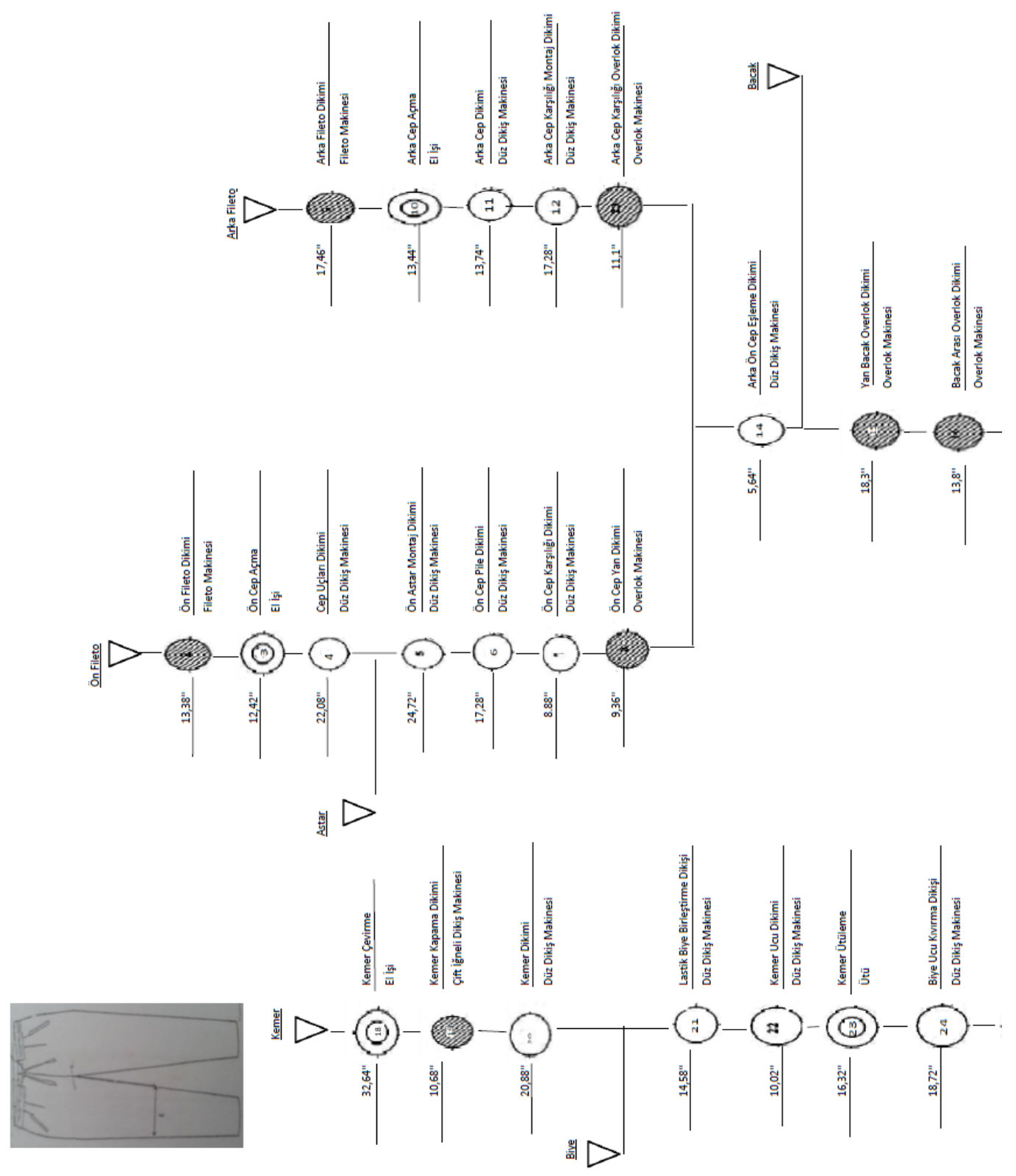

Şekil 5. 2 nolu ürünün proses analiz tablosu 


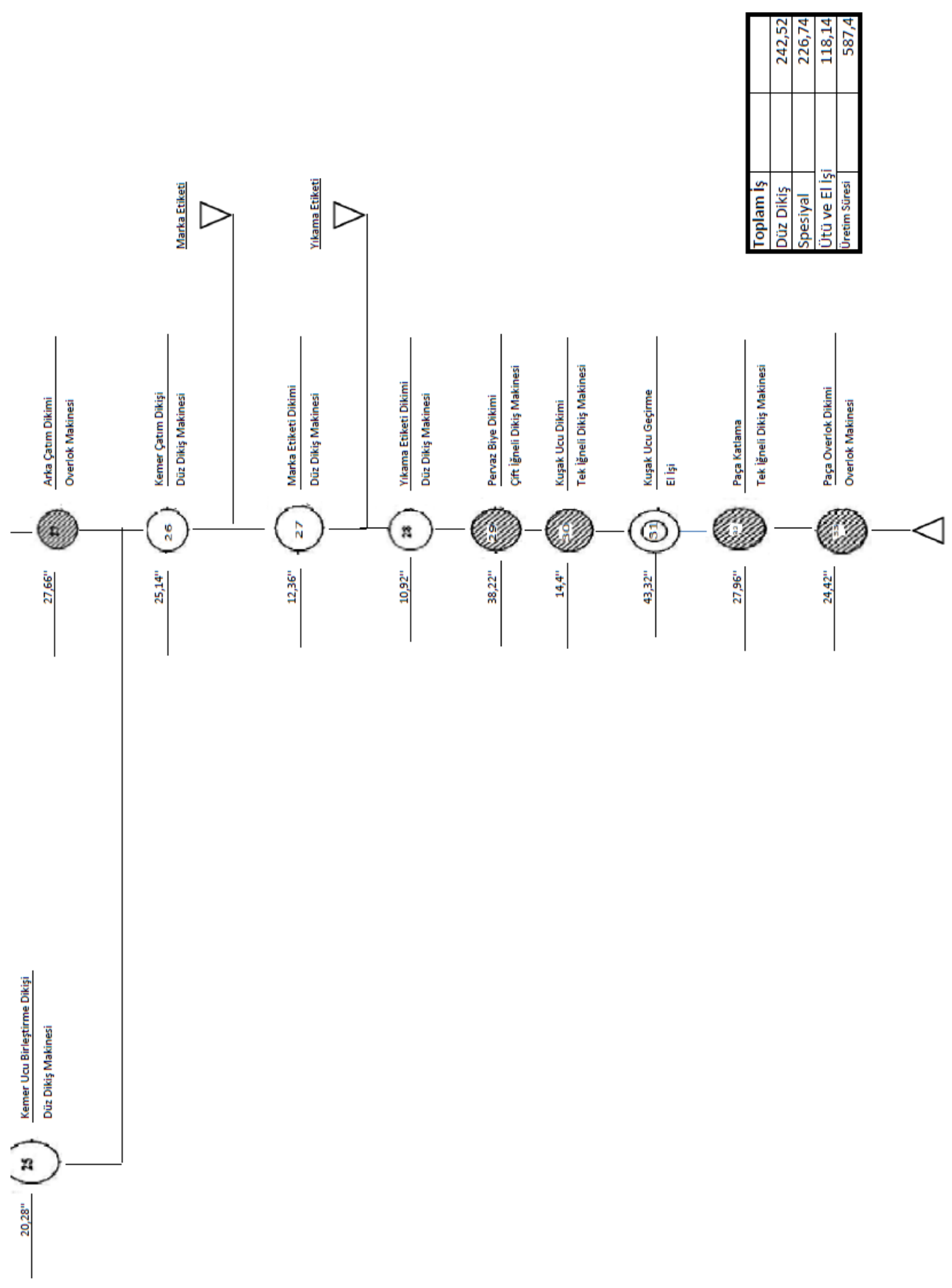

Şekil 5. 2 nolu ürünün proses analiz tablosu (devamı) 
Çizelge 6. 1 nolu üründe proseslere ayrılan süreler

\begin{tabular}{|c|c|c|c|c|}
\hline $\begin{array}{c}\text { Proses } \\
\text { No }\end{array}$ & Proses Adı & $\begin{array}{c}\text { Standart } \\
\text { Proses Süresi } \\
(\text { (sn) }\end{array}$ & Operatör Sayısı & Ayrılan Standart Proses Süresi (sn) \\
\hline 1 & Fileto Yeri İşaretleme & 7,08 & 1 & \multirow{6}{*}{$118,74 / 9=13,19$} \\
\hline 3 & Ön Cep Açma & 17,88 & 2 & \\
\hline 10 & Arka Cep Açma & 16,14 & 1 & \\
\hline 18 & Kemer Çevirme & 25,08 & 2 & \\
\hline 23 & Kemer Ütüleme & 12,78 & 1 & \\
\hline 31 & Kuşak Ucu Geçirme & 39,78 & 2 & \\
\hline 2 & Ön Fileto Dikimi & 16,5 & 1 & \multirow{8}{*}{$143,4 / 16=8,96$} \\
\hline 8 & Ön Cep Yan Dikimi & 9,66 & 2 & \\
\hline 9 & Arka Fileto Dikimi & 14,04 & 2 & \\
\hline 13 & Arka Cep Karşıllı̆ı Overlok Dikimi & 13,56 & 3 & \\
\hline 15 & Yan Bacak Overlok Dikimi & 15,3 & 2 & \\
\hline 16 & Bacak Arası Overlok Dikimi & 22,56 & 3 & \\
\hline 17 & Arka Çatım Dikimi & 27,3 & 2 & \\
\hline 33 & Paça Overlok Dikimi & 24,48 & 1 & \\
\hline 4 & Cep Uçları Dikimi & 17,88 & 1 & \multirow{7}{*}{$112,68 / 10=11,26$} \\
\hline 5 & Ön Astar Montaj Dikimi & 26,82 & 2 & \\
\hline 6 & Ön Cep Pile Dikimi & 11,7 & 3 & \\
\hline 7 & Ön Cep Karşılığı İçi Dikimi & 11,7 & 1 & \\
\hline 11 & Arka Cep Dikimi & 18,54 & 1 & \\
\hline 12 & Arka Cep Karşılığı Montaj Dikimi & 16,68 & 1 & \\
\hline 14 & Arka Ön Cep Eşleme Dikimi & 9,36 & 1 & \\
\hline 19 & Kemer Kapama Dikimi & 21,36 & 1 & \multirow{4}{*}{$84,72 / 8=10,59$} \\
\hline 29 & Pervaz Biye Dikimi & 24,36 & 2 & \\
\hline 30 & Kuşak Ucu Dikimi & 14,94 & 2 & \\
\hline 32 & Paça Katlama & 24,06 & 3 & \\
\hline 20 & Kemer Dikimi & 24,06 & 2 & \multirow{8}{*}{$142,74 / 13=10,98$} \\
\hline 21 & Lastik Biye Birleştirme Dikimi & 12,3 & 1 & \\
\hline 22 & Kemer Ucu Dikimi & 16,8 & 2 & \\
\hline 24 & Biye Ucu Kıvırma Dikişi & 18,18 & 2 & \\
\hline 25 & Kemer Ucu Birleştirme Dikişi & 13,56 & 1 & \\
\hline 26 & Kemer Çatım Dikimi & 24,78 & 2 & \\
\hline 27 & Marka Etiketi Dikimi & 20,16 & 2 & \\
\hline 28 & Yıkama Etiketi Dikimi & 12,9 & 1 & \\
\hline
\end{tabular}




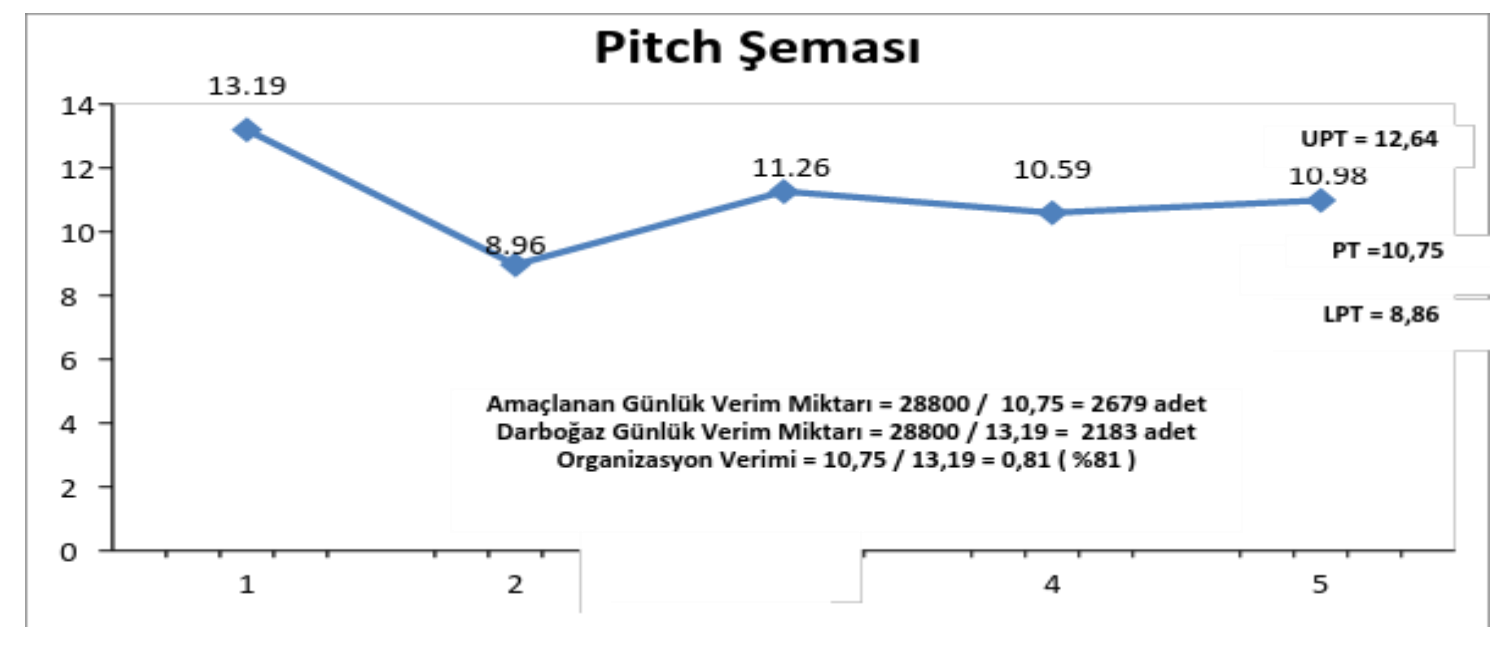

Şekil 6. 1 nolu ürünün pitch şeması

Organizasyon Verimi $=P T /$ Darboğaz İşlem Süresi

Organizasyon Verimi $=10,75 / 11,28=0,95$

Bu yapılan yeni işlem ile organizasyon verimi $\% 81$ 'den \%95'e çıkarılmış olur.

\subsubsection{2 nolu Ürünün Dikim Bandı Verimlilik Artırma Çalıșmaları}

1 nolu ürün dikim prosesi için yapılmış olan verimlilik çalışmaları 2 nolu ürün için de yapılmıştır. PT, alt kontrol sınırı ve üst kontrol sınırları hesaplanmıştır. 2 nolu ürün için hesaplanan standart üretim süresi 587,4 saniye, işçi sayısı ise 53'tür. Buna göre yapılan hesaplamalarda;

$\mathrm{PT}=587,4 / 53=11,08 \mathrm{sn}$

$\mathrm{UPT}=11,08 / 0,85=13,03 \mathrm{sn}$

LPT $=2 \times 11,08-13,03=9,13$ sn olarak hesaplanır.

2 nolu üründe her bir işlem için çalışması gereken işçi sayıları; düz dikiş için 22, overlok ve fileto dikiş için 12, çift iğneli ve tek iğneli dikiş için 8 , el işi ve ütü için 11' dir. Çizelge 7'de 2 nolu ürünün proseslere ayrılan süresi bulunmaktadır. Çizelge 7, PT, alt kontrol sinır1 ve üst kontrol sinır1 kullanılarak oluşturulmuş Pitch şeması ise Şekil 7 ile gösterilmiştir.

Pitch Şemasına göre dar boğaz noktası şemadaki en yüksek değer olan 13,12'dir. Hesaplanan değerler ve oluşturulan pitch şeması gözlendiğinde el işi ve ütü proseslerinin standart sürelerinin üst kontrol sınırının üstünde olduğu görülmektedir. Proses süresi $13,12 \mathrm{sn}$, üst kontrol sınırı ise 11,08 sn'dir. Kemer çevirme ve kemer ütüleme prosesleri, Pitch Time'in altında kalan $3,4,5,6,10,11$ ve 13 nolu proses grubu ile birleştirilebilir.

Bu şekilde yapılan hesaplama;

$[118,14-(32,64+16,32)] / 6=11,53$ sn’ye düşürülerek üst kontrol sınırını aşması engellenerek Pitch Time'a yaklaştırılmış olunur . Böylece yeni dar boğaz süresi 11,53 sn olur.

$3,4,5,6,10,11$ ve 13 nolu proseslerin birleştirilmesiyle oluşan yeni işlem süresi;

$[109,62+(32,64+16,32)] / 14=11,32$ sn'ye yükseltilerek Pitch Time’a yaklaşılmış olur. 
Çizelge 7. 2 nolu üründe proseslere ayrılan süreler

\begin{tabular}{|c|c|c|c|c|}
\hline $\begin{array}{l}\text { Proses } \\
\text { No }\end{array}$ & Proses Adı & $\begin{array}{l}\text { Standart Proses } \\
\text { Süresi (sn) }\end{array}$ & Operatör Sayısı & Ayrılan Standart Proses Süresi (sn) \\
\hline 1 & Ön Fileto Dikimi & 13,38 & 1 & \multirow{8}{*}{$135,48 / 13=10,42$} \\
\hline 7 & Ön Cep Yan Dikimi & 9,36 & 1 & \\
\hline 8 & Arka Fileto Dikimi & 17,46 & 1 & \\
\hline 12 & $\begin{array}{l}\text { Arka Cep Karşıllı̆ı Overlok } \\
\text { Dikimi }\end{array}$ & 11,1 & 1 & \\
\hline 14 & Yan Bacak Overlok Dikimi & 18,3 & 3 & \\
\hline 15 & Bacak Arası Overlok Dikimi & 13,8 & 3 & \\
\hline 16 & Arka Çatım Dikimi & 27,66 & 2 & \\
\hline 32 & Paça Overlok Dikimi & 24,42 & 1 & \\
\hline 2 & Ön Cep Açma & 12,42 & 1 & \multirow{5}{*}{$118,14 / 9=13,12$} \\
\hline 9 & Arka Cep Açma & 13,44 & 1 & \\
\hline 17 & Kemer Çevirme & 32,64 & 2 & \\
\hline 22 & Kemer Ütüleme & 16,32 & 1 & \\
\hline 30 & Kuşak Ucu Geçirme & 43,32 & 4 & \\
\hline 3 & Cep Uçları Dikimi & 22,08 & 2 & \multirow{7}{*}{$109,62 / 11=9,96$} \\
\hline 4 & Ön Astar Montaj Dikimi & 24,72 & 2 & \\
\hline 5 & Ön Cep Pile Dikimi & 17,28 & 2 & \\
\hline 6 & Ön Cep Karşılı̆̆ı İçi Dikimi & 8,88 & 1 & \\
\hline 10 & Arka Cep Dikimi & 13,74 & 1 & \\
\hline 11 & $\begin{array}{l}\text { Arka Cep Karşılığı Montaj } \\
\text { Dikimi }\end{array}$ & 17,28 & 2 & \\
\hline 13 & Arka Ön Cep Eşleme Dikimi & 5,64 & 1 & \\
\hline 18 & Kemer Kapama Dikimi & 10,68 & 1 & \multirow{4}{*}{$91,26 / 8=11,4$} \\
\hline 28 & Pervaz Biye Dikimi & 38,22 & 3 & \\
\hline 29 & Kuşak Ucu Dikimi & 14,4 & 2 & \\
\hline 31 & Paça Katlama & 27,96 & 2 & \\
\hline 19 & Kemer Dikimi & 20,88 & 2 & \multirow{8}{*}{$132,9 / 12=11,07$} \\
\hline 20 & Lastik Biye Birleştirme Dikimi & 14,58 & 2 & \\
\hline 21 & Kemer Ucu Dikimi & 10,02 & 1 & \\
\hline 23 & Biye Ucu Kıvırma Dikişi & 18,72 & 2 & \\
\hline 24 & Kemer Ucu Birleştirme Dikişi & 20,28 & 1 & \\
\hline 25 & Kemer Çatım Dikimi & 25,14 & 2 & \\
\hline 26 & Marka Etiketi Dikimi & 12,36 & 1 & \\
\hline 27 & Yıkama Etiketi Dikimi & 10,92 & 1 & \\
\hline
\end{tabular}




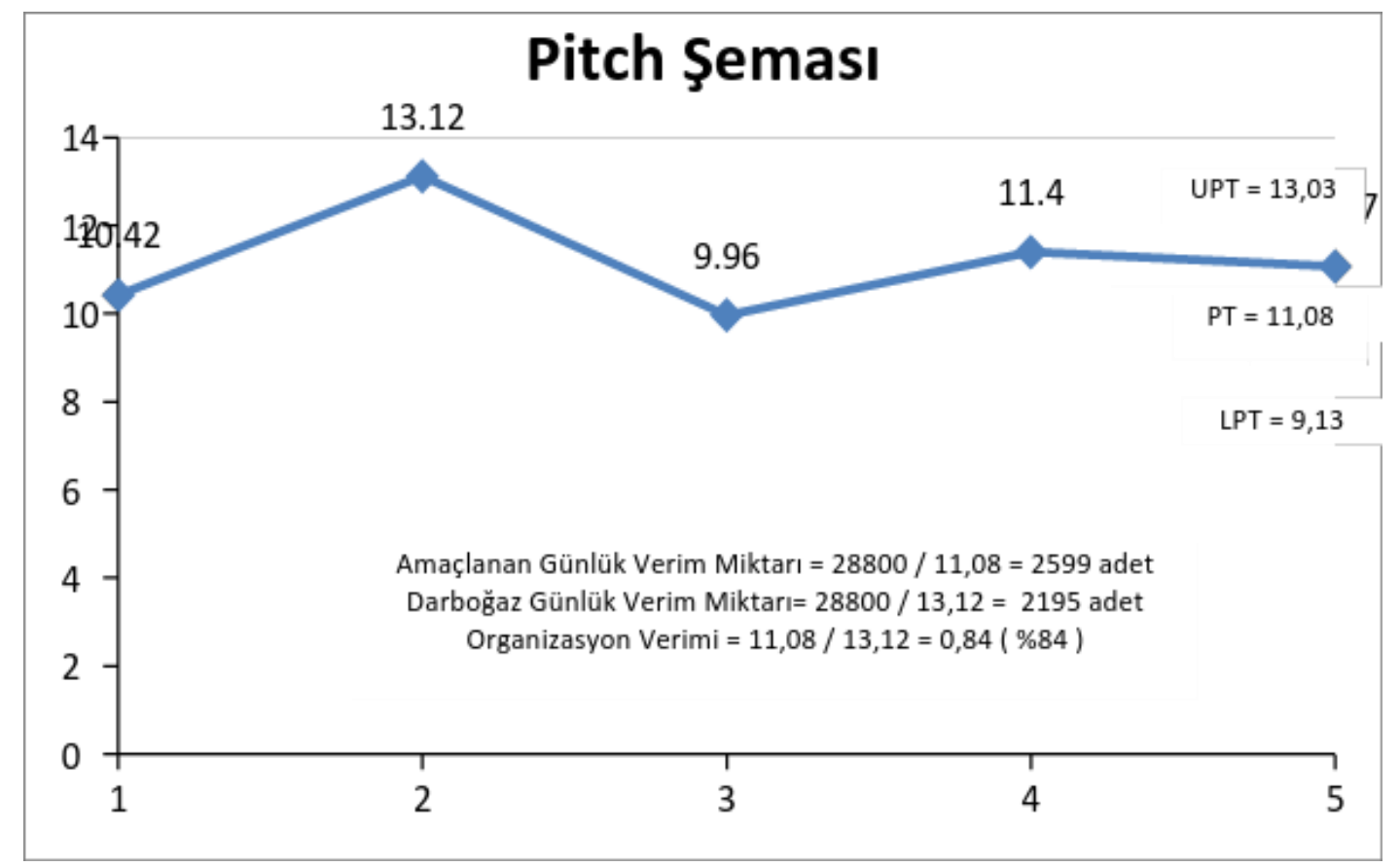

Şekil 7. 2 nolu ürün pitch şeması

Dikim bandında amaçlanan günlük verim, darboğazın günlük verimi ve organizasyon verimi aşağıdaki formüllerle yeniden hesaplandığında;

Amaçlanan Günlük Verim = $28800 / 11,08=2599$ adet

Darboğaz Günlük Verim $=28800 / 11,53=2498$ adet

Organizasyon Verimi $=11,08 / 11,53=0,96$

Organizasyon verimi \%84'ten \%96'ya çıkarılmış olur.

\section{SONUÇ}

Konfeksiyon sektöründe emek yoğun çalışılması verimlilik çalışmalarının yapılmasını önemli hale getirmiştir. Bu çalışmada aynı modelde desenli ve desensiz iki pantolon üzerinde verimlilik çalışmaları yapılmıştır. Dikim bölümünde proses tablosu oluşturulmuş, zaman ölçümü yapılmış, pitch time, üst kontrol sınırı ve alt kontrol sınırı bulunmuştur. Pitch şeması oluşturularak, dikim bandının verimliliği artırılmıştır. Önerilen dikim planları gerçekleştirildiğinde; desenli kumaştan dikilen pantolonun organizasyon verimliliği, desensiz (düz renkli) kumaştan dikilen pantolonla kıyaslandığında daha çok artırılmıştır. $\mathrm{Bu}$ durumun desenli pantolonun dikiminde desen uyumu için dikkat edilmesi noktaların ve işlem adımlarının daha fazla olmasından kaynaklandığı saptanmıştır.

\section{KAYNAKLAR}

1. İTKİB-Hazırgiyim ve Konfeksiyon Sektörü 2014. Ocak-Mart İhracat Performans Değerlendirmesi, İTKİB Genel Sekreterliği Ar \& Ge ve Mevzuat Şubesi, Nisan 2014.

2. http://tr.wikipedia.org/ İş Etüdü, Güncelleme Tarihi :1 Ağustos 2013.

3. Kanat S., Güner M., 2007. Tekstil ve Konfeksiyon İşletmelerinde Verimlilik Ölçümü, Tekstil ve Konfeksiyon, Sayı 4, 279283. 
4. Duru Baykal P., Tunç M. 2011. Bornoz Dikiminde Üretim Yönetimi Üzerine Bir Çalışma, Çukurova Üniversitesi Mühendislik Mimarlık Fakültesi Dergisi, Sayı 26(2), 9-17,

5. Yüce Ö., Güner M., Giysi Dikim Süresine Etki Eden Faktörlerin Analizi, Tekstil ve Konfeksiyon, Say1 1, 41-48, 2008.

6. Duru Baykal P., Göçer E., 2012. Konfeksiyonda Kumaş ve Model Çeşitliliğinin Üretimde Kalite ve Verimliliğe Etkisi, Tekstil ve Mühendis, Sayı 19:87, 15-23,

7. Kansoy, O., Erdoğan, M.Ç. 2006. Giysi Model Özelliklerinin Parça Sayısı, Parça Çevresi, ve Dikim Süresi ile İlişkileri, Tekstil ve Konfeksiyon, Sayı 1, S. 320-327.

8. Aytek Konfeksiyon, İşletme Bilgileri, Adana, 2014.

9. JUKI- 1999. Konfeksiyonda Üretim Yönetimi Semineri, Yönetici Eğitim Kursu El Kitab1, Hazır Giyim Üretimi Araştırma Laboratuvarı, JUKI Corporation, 122s.

10. Duru Baykal, P., 2008. Konfeksiyonda Üretim Yönetimi, Ders Notu, Çukurova Üniversitesi, Tekstil Mühendisliği Bölümü, Adana, 60s.,

11. Tunç, M., 2010. Havlu ve Bornoz Üretim Sürecinin İncelenmesi, Yüksek Lisans Tezi, Çukurova Üniversitesi Fen Bilimleri Enstitüsü, Adana. 